\title{
The Future of Nurse Education: Imagining the art of the possible
}

Professor Debbie Roberts and Professor Jacqueline Leigh

We are writing this paper at a time whereby nursing is in the spotlight as never seen before. The nursing profession in the UK and globally are providing nursing care amidst the COVID-19 pandemic, that is throwing up immense challenges to the way that person centred care is delivered in those clinical settings that have rapidly changed to meet acutely ill patients' needs.

In times of crisis, the NMC together with each of the four UK country commissioning partners and NHS Staff Council mobilised the student healthcare workforce through implementing emergency standards and creating national roles such as aspirant nurse (Health Education England 2020, NHS Staff Council 2020, NMC 2020). Taking on these roles, there have been amazing examples of student nurses supporting patients as they died in hospital without loved ones and comforting patients crying through sadness, fear or pure exhaustion (Leigh et al. 2020a).

September 2020 will see the removal of the NMC Emergency Standards, with the NMC reverting to its 2018 Standards (NMC 2018). We expect that providing person centred care during a pandemic or amidst a crisis or yet another crisis will become the new normal. Indeed, managing major incidents is highlighted within the new NMC (2018: 23) educational standards, as a proficiency that all new graduates must master:

"6.12 understand the role of registered nurses and other health and care professionals at different levels of experience and seniority when managing and prioritising actions and care in the event of a major incident".

So, the intention for nurses to be confident in these situations will remain in place.

Covid-19 whilst extreme, in terms of a major incident, can be used as an example of how HEls and its partner healthcare organisations have needed to think creatively about delivering nurse education and have demonstrated how when working collaboratively, student nurses have transitioned into their first registered nurse role. Universities have also needed to rapidly replace first year students practice hours with theory due to their practice learning being paused (NMC 2020). Even though students can resume their practice learning, the capacity of healthcare organisations to accommodate students is greatly reduced and this is due to reconfiguration of healthcare services and a reduction in the offer of community learning opportunities. Universities in September 2020 will be welcoming its next cohort of student nurses, compounding the need for further placements, providing the perfect storm around bottlenecks for quality practice learning opportunities for all student nurses.

Thinking about the pipeline for registered nurses and the transition of students to registered nurse: what if we were to create a perfect nurse education curriculum- something that we feel is currently elusive!? What if HEl's and their healthcare partners were not constrained by student fees and capped numbers; securing practice learning opportunities for first- and second-year students, what could we do with nurse education? Yes, we would have to take risks, let's just think about what might be possible if we were able to be bold and brave with our curriculum design. We are clear that we are advocates of graduate nurses of whom are critical thinkers and that during their pre-registration nursing programme, students are provided with the quality nursing curriculum and practice learning experience. In this paper, we will not be debating the issue of work contracts, paid learning experiences, student rights or the debate around if low paid on the job nursing students training will take the profession backwards. Others such as Leary (2020) provide this discussion. Instead we offer our thoughts around the future curriculum possibilities, and we welcome further discussion on the 
issues and recommendations that we make, for example have a clear vision for nursing -be bold about the role of the nurse and be clear about the future of nursing. We fully acknowledge that the NMC did develop the new educational standards following a two-year consultation process, a process where 1,563 responses to consultation 1 (including 268 responses from organisations) and 706 responses to consultation 2 (including 120 responses from organisations); were received (NMC 201b). In September 2019, there were 706,252 individuals on the register (NMC 2019).

\section{Learning from the medical model of education: building on the best parts}

What if we could have a model that imitates that of medical education? Medical education in the UK is wide and diverse. On average, undergraduate courses last between 4 and 6 years. After their undergraduate training, newly qualified doctors undergo 2 years of foundation programme training before choosing a specialty. The 2-year foundation programme was set up to ensure that all newly qualified doctors followed a structured programme of study and practical experience before progressing to specialist training. This is a two-year training programme for newly qualified doctors, thus acknowledging that learning is a lifelong event and contains a number of transitional and developmental stages. After successful completion of the first year, the General Medical Council grants individual's full registration with a licence to practise. This is necessary to practise as a doctor in the UK.

Taking the core concepts of medical education, we propose a nursing programme structure (see Box 1 and 2):

Features of year 1, 2\&3: student status to graduate nurse (See Box 1)

Concept based curriculum: based on nursing concepts. According to Repsha, Quinn and Peters (2020: 67) a concept-based curriculum avoids an overcrowded curriculum as it "focuses on teaching core ideas or concepts threaded throughout a curriculum to encourage critical thinking and deeper learning". The approach tends to favour problem-based learning, team-based learning, case studies, and reflection in order to promote deeper learning. When implemented successfully, the approach is said to empower students in their learning, fostering increased autonomy and greater engagement, and enables learners to integrate knowledge and apply it to clinical practice (Repsha, Quinn and Peters 2020).

Narrative pedagogy: Teachers seek to establish partnerships with students in a lifelong quest for knowledge. Together they form a reciprocal community of learners who explore how and in what ways one becomes a nurse. The teacher uses real life practice narrative (as case studies) to reinforce the centrality of the lived experience and learning is said to take place through dialogue and attention to nursing practices (Nehls 1995). The person is the focus of the dialogue, ensuring the centrality of humanistic person-centred discussions. The underlying assumption to this concept is that the teacher is also a learner. As teacher and students share personal practices, the students come to appreciate that nursing knowledge can evolve by reflection on experience. By examining their own experience as well as that of others is suggested that the students begin to recognise where they need to focus their attention. The narrative pedagogy seeks to establish dialogue and connections between members of the group which enables the students to see the importance of reflecting on practice not just to learn but also as a means to contribute to nursing knowledge. Also applying the concept of Signature pedagogies (Shulman 2005) ensures that all teaching is fundamentally organised in a way that ensures student nurses are educated in readiness for their new profession. 
We propose how in years one and two of the nurse education programme, students would learn the theory of nursing and begin to apply the theory through the judiciously selected case studies. The people described within the case studies would then be 'brought to life' through standardised patients and mannequins as students meet those individuals within simulated or immersive learning environments. The curriculum is driven by a series of unfolding case studies as described by Mills et al (2014). Here students could begin to learn how to apply the theories that have learned about to realistic low-risk situations. Students could move between classroom and immersive experiential learning in a fluid manner in each week of the programme. Each period of simulation would be built upon through structured de-brief and reflection on practice; thus, expanding the students' nursing repertoire and knowledge. Theory and practice are merged and the (artificial) boundaries between the two become blurred.

We recommend authentic methods of formative and summative assessment, those that mirror what student nurses may encounter as an NMC registrant. Take for example the Patchwork Text Assessment whereby teachers carefully guide students through a sequence of short assessment tasks (or patches) relating to a range of pre-determined activities designed to cover the intended learning outcomes of the module (Scoggins and Winter 1999, Winters 2003, Leigh et al. 2013). Each patch is complete and the overall unity of these component sections, although planned in advance, is finalised retrospectively when they are 'stitched' together at the end of the module (Brunsden 2005) through for example the reflective critical commentary (Leigh et al. 2013).

It is recognised that existing graduates whose ambition is to become a registered nurse may fast track year one and two.

In year 3, students will have the opportunity to gain broad clinical experience in a series of quality practice learning experiences in a variety of specialties/healthcare/voluntary, community and social enterprise (VCSE) settings. Supernumerary status is supported by practice supervisors with protected time to teach (NMC 2018b). Interprofessional practice experience is a fundamental and key component of year 3 and we propose the concept of Academy areas, characterised by a clear commitment to inter-professional practice learning; the presence of highly skilled committed healthcare professionals who actively seek out teaching opportunities with learners; and have a track record of person-centred practice and associated development. At the end of year 3, graduate status is granted and once the student meets programme requirements is granted NMC registration.

For fast track programmes, graduate status will take 2 years (year 3 becomes year 2).

Features of year 4 - The Fully Registered Nurse (See Box 1.)

As the fully registered nurse, year 4 comprises of paid deployment. The internship provides the opportunity for the registered nurse to both work and learn in practice. Organised in two three-month placements in areas of the students choosing, this is followed by six months intense transition into a substantive post. Our internship will mitigate against the long- standing problems associated with shock when transitioning from student to registered nurse (Darvil and Leigh 2018), often characterised by new graduates engaging in a professional practice role of whom are confronted with a broad range of emotional, physical, intellectual, developmental and socio-cultural changes (Boychuk Duchscher 2007, Kramer 1974). 


\begin{tabular}{|l|l|l|}
\hline Year 1 & $\begin{array}{l}\text { Introductory theory, taught through real world case studies and } \\
\text { narrative pedagogy, supported by immersive simulation. Reflecting } \\
\text { on practice to build on knowledge. }\end{array}$ & Student status \\
\hline Year 2 & $\begin{array}{l}\text { Introductory theory, taught through real world case studies and } \\
\text { narrative pedagogy, supported by immersive simulation. Reflecting } \\
\text { on practice to build on knowledge. }\end{array}$ & Student status \\
\hline Year 3 & $\begin{array}{l}\text { The emphasis remains on the student as learner. Students will have } \\
\text { the opportunity to gain broad clinical experience in a series of } \\
\text { placements/academy areas in a inatuate status: } \\
\text { specialties/healthcare/voluntary, community and social enterprise } \\
\text { (VCSE) settings. They will experience interprofessional learning } \\
\text { placements. Supernumerary status, supported by practice } \\
\text { supervisors (with protected time to teach). Interprofessional } \\
\text { practice experience. Theoretical principles are revisited through } \\
\text { weekly small group reflective tutorials, facilitated by nurse } \\
\text { educators. Students are assessed through a series of clinical viva's } \\
\text { (Roberts 2013), where they demonstrate an integration of } \\
\text { theoretical principles and application to practice. }\end{array}$ & \\
\hline Year 4 & $\begin{array}{l}\text { Paid deployment } \\
\text { Internship working and learning in practice. Two three-month } \\
\text { placements in areas of the students choosing; allowing the students } \\
\text { to start to think about specialising in a particular area of nursing } \\
\text { practice (this could include practice learning/placement alongside } \\
\text { research nurses, specialist nurses, advanced nurse practitioners, } \\
\text { service leads, managers or educational leaders, followed by six } \\
\text { months intense transition into a substantive post. }\end{array}$ & \\
\hline
\end{tabular}

Year 5 \& 6: Postgraduate development (See Box 2.)

Our model for postgraduate development of expertise can be initiated at any point in a nurse's career trajectory; recognising that some nurses will remain as a fully registered nurse (after year four) for many years, others may wish to progress to expertise immediately. Our postgraduate development trajectory (Box 2.) offers clinical, leadership and HEl pathways.

Box 2: Post graduate programme:

\begin{tabular}{|l|l|l|}
\hline Year 5 & $\begin{array}{l}\text { Post graduate development of expertise in evidence based clinical } \\
\text { practice (Translation fellows. Masterson et al. 2020), practice-based } \\
\text { learning and education, or leadership and influence (NHS } \\
\text { Leadership Academy 2020). Accompanied by an integrated post } \\
\text { graduate programme; supported one day per week protected } \\
\text { learning time in University (or equivalent). Freedom to seek out } \\
\text { learning opportunities and work alongside other experts in the field; } \\
\text { including industry and entrepreneurs, or a career trajectory into } \\
\text { higher education. }\end{array}$ & $\begin{array}{l}\text { MSc, recognised } \\
\text { on the Register of } \\
\text { Expertise. }\end{array}$ \\
\hline Year 6 & $\begin{array}{l}\text { Focused on innovation and evaluation of impact in chosen field of } \\
\text { expertise. }\end{array}$ & \multicolumn{2}{|c|}{} \\
\hline
\end{tabular}




\section{Conclusion}

Educating nurses amidst a global crisis may become the new norm and indeed this paper is written after having reflecting on nurse education that is currently in the spotlight due to the COVID-19 pandemic. We have offered our thoughts around the future possibilities of nurse education and we recommend a clear vision for nursing - being bold about the role of the nurse that is clearly embedded within a pre- registration nursing curriculum. We suggest imitating UK medical education. To avoid overcrowding, we recommend implementing a concept-based curriculum that will focus curriculum designers on teaching core ideas or concepts that are threaded throughout a curriculum. Application of narrative pedagogy will enable students to see the importance of reflecting on practice, not just to learn, but also to contribute to new nursing knowledge. Applying the concept of Signature pedagogies also ensures that all teaching is fundamentally organised in a way that ensures student nurses are educated in readiness for their new profession. Our nursing programme structure re-thinks nursing that provides the trajectory from student nurse through to graduate nurse. The balance of theory, authentic assessment, quality practice learning experiences coupled with an internship will promote the smooth role transition from student to fully registered nurse and for a nursing career that supports continuing professional development.

Postgraduate trajectories are exciting as we propose Academy areas ensuring that our nurse academics (teachers) remain in close contact with practice areas ensuing that our nurses are supported through different pathways such as research, clinical, leadership and education (HEI and practice).

We welcome further discussion on the issues and recommendations that we make; and write this paper in the spirit of seeking to constantly improve nurse education, and nursing practice.

\section{References:}

Boychuk Duchscher, J. 2007 Professional Role Transition into Acute-Care by Newly Qualified Graduated Baccalaureate Female Registered Nurses. Unpublished PhD thesis. Edmonton, Canada: University of Alberta

Brunsden, V. 2005. Blending Research \& Teaching in the Classroom Using Patchwork Text Assessments to Simulate the Research Process, Higher Academy Psychology Network, R \& T Case, 11, 8.

Darvill A., and Leigh JA., 2018 Transition resilience: an evaluation of the perspectives of preparation for transition of final year undergraduate nursing students, The International Journal of Practice-based Learning in Health \& Social Care

Health Education England 2020 Standard Operating Procedure for the Deployment of Nursing and Midwifery Students in the North West of England, Manchester, HEE 
Kramer, M. 1974 Reality Shock: Why Nurses Leave Nursing. St Louis: Mosby

Leary A., (2020) Low paid on the job nursing students training will take the profession backwards, Nursing Standard, posted $1^{\text {st }}$ July 2020, https://rcni.com/nursing-standard/students/nursingstudies/low-paid-job-nursing-student-training-will-take-profession-backwards-162526

Leigh JA., Bolton M., Cain K., Yates Bolton N., Harrison N., Ratcliffe S., 2000a Nursing on the Frontline during the COVID-19 Pandemic - reflections from student nurses, newly qualified graduate nurses and personal tutor, British Journal of Nursing, in press

Leigh J. A., Rutherford J., Wild J., Cappleman J., \& Hynes C. 2013 The Patchwork Text Assessment - An Integral Component of Constructive Alignment Curriculum Methodology to Support Healthcare Leadership Development, Journal of Education and Training Studies, 1 (1): 139-150

Masterson. A., Lee. G., Khan. E., Titchener. K., Doyle-Blunden. J., Metcalfe. A., Tee. S., and Bliss. J. 2020 Redefining the role of the nurse academic in practice: A pilot study. Nurse Education in Practice. 44. 102750.

Mills. J., West. C., Langtree. T., Usher. K., Henry. R., Chamberlain-Salaun. J. and Mason. M. 2014. 'Putting it together': Unfolding case studies and high-fidelity simulation in the first-year of an undergraduate nursing curriculum. Nurse Education in Practice. 14. 12-17.

Nehls N. 1995. Narrative Pedagogy: Rethinking Nursing Education. Journal of Nursing Education. 34 (5) 204-210.

NHS Leadership Academy (2020) https://www.leadershipacademy.nhs.uk/ (Accessed $3^{\text {rd }}$ July 2020)

NHS Staff Council. Deployment of student nurses during the COVID-19 emergency. 2020. (accessed 29 May 2020) https://tinyurl.com/ybttk6cl

Nursing and Midwifery Council. Future nurse: standards of proficiency for registered nurses, London: NMC; 2018a. accessed 3/7/20 via: https://tinyurl.com/yaln93xh

NMC 2018b. Education Standards Consultation Response. Accessed 3/7/20 via: https://www.nmc.org.uk/globalassets/sitedocuments/education-standards/education-standardsconsultation-reponse-may-2018.pdf

NMC 2019 Mid-Year Update Accessed on 3/7/20 via: https://www.nmc.org.uk/globalassets/sitedocuments/other-publications/nmc-register-dataseptember-2019.pdf

Nursing and Midwifery Council (NMC 2020) Emergency standards for nursing and midwifery education, London, NMC: (accessed 24th April 2020). https://www.nmc.org.uk/globalassets/sitedocuments/education-standards/emergency-standardsfor-nursing-and-midwifery-education.pdf 
Repsha. CL., Quinn. B.L., and Peters. A.B. 2020. Implementing a Concept-Based Nursing Curriculum: A Review of the Literature. Teaching and Learning in Nursing. 15. 66-71.

Roberts D. 2013. The clinical viva: An assessment of clinical thinking. Nurse Education Today 33 (2013) 402-406.

Scoggins, J., \& Winter, R. 1999. The Patchwork Text: a coursework format for education as critical understanding. Teaching in Higher Education, 4(4), 485-99.

Winters. 2003. Contextualizing the Patchwork Text: Addressing Problems of Coursework Assessment in Higher Education. Innovations in Education and Teaching International, 40(2), 112-122. 